\title{
A Política Pública de Regionalização do Turismo em Minas Gerais: os circuitos turísticos
}

\section{A Tourism Public Policy of Regionalization in the State of Minas Gerais: the tourist circuits}

Luana Emmendoerfer ${ }^{1}$

\begin{abstract}
Resumo
O objetivo desta pesquisa foi analisar o desenvolvimento do turismo por meio das políticas públicas de regionalização, a partir do estudo de caso realizado nos Circuitos Turísticos em Minas Gerais, praticados pela Secretaria de Estado de Turismo de Minas Gerais - SETUR. Entende-se que o conhecimento deste processo que envolve várias ações poderia ser aplicado em outros estados da federação como forma de incremento mais abrangente num contexto nacional, visto que o Plano Nacional do Turismo (PNT) institui que para um andamento adequado das ações de turismo junto aos estados da federação, deve-se proceder de forma regionalizada. Desta forma, foi realizada uma revisão teórica como tentativa de elucidar informações sobre o objeto de estudo, que possibilitou verificar como principal resultado a forma descentralizada do planejamento da política pública de turismo, sendo possível de ser implantada e desenvolvida promissoramente através de ações pelo estado.
\end{abstract}

Palavras-Chave: política pública, desenvolvimento turístico, circuitos turísticos.

\begin{abstract}
The focus of this research was to analyze the relation of the state with the development of the tourism by means of the regional public politics, from the studies case done of the Tourist Circuits in Minas Gerais, done by Secretary of Tourism of State of Minas Gerais. One understands that the knowledge of this process that involves some actions could be applied in other states of the federacy as form of more including increment in a national context, since the National Plan of the Tourism (NPT) institutes that for an adequate course of the actions of together tourism to the states of the federacy, it must be developed in a regional form. Thus, this form was carried through a theoretical revision as an attempt to elucidate information on the study object, that the decentralized form of the planning of the public politics of tourism made possible to verify as main result, being possible to be implanted and developed in a promising way through actions for the state.
\end{abstract}

Keywords: public politics, tourist development, tourist circuits.

\footnotetext{
${ }^{1}$ Bacharel em Turismo e Hotelaria pela Universidade do Vale do Itajaí - UNIVALI. Técnica na Atividade Turismo Social-SESC/SC. E-mail: luaemme@brturbo.com.br
} 


\section{Introdução}

As potencialidades do turismo no Brasil favorecem o desenvolvimento deste setor. O mercado brasileiro apresenta vantagens comparativas baseadas na diversidade de destinos turísticos e na oferta de preços competitivos. O país detém as condições necessárias para gerar resultados econômicos e sociais de forma sustentável. O turismo, porém, tem um caráter complexo e dinâmico e, por essa razão, parte-se do pressuposto nesta pesquisa que as ações sejam definidas e colocadas em prática de forma planejada.

Em Minas Gerais, o planejamento para o desenvolvimento turístico ocorre por meio dos Circuitos Turísticos, considerados a principal ação política realizada pela Secretaria de Estado de Turismo - SETUR, a qual está associada ao Plano Nacional de Turismo - PNT. Esta estratégia foi idealizada como meio para se estruturar a atividade turística municipal e regional, buscando atrair mais turistas a determinada região, bem como estimular sua permanência ali por um tempo maior e, conseqüentemente, movimentar o comércio e os serviços turísticos locais.

Diversas regiões de Minas apostaram na estratégia deliberada dos Circuitos Turísticos e vêm se mostrando muito empenhadas no alcance de seus objetivos. Mediante o associativismo, buscam superar as dificuldades na mobilização para o desenvolvimento do turismo local, vislumbrando assim novos horizontes, atentando-se para aspectos que possam representar oportunidades.

Portanto, é ponto pacífico reconhecer no planejamento do turismo uma alternativa de desenvolvimento e crescimento sustentável. Sendo assim, tornar-se necessário o envolvimento do poder público, iniciativa privada, dos empresários, estudantes e moradores das diversas comunidades, e de toda população. Iniciar um trabalho inovador e digno das riquezas naturais e culturais é o ponto chave, pois investir em turismo é estar respaldado em uma tendência histórica mundial de crescimento constante e promissor.

Mas para se ter compreensão clara da efetividade do planejamento turístico em termos de geração de emprego, renda e desenvolvimento sustentável, é preciso conhecer o seu processo de idealização e execução por parte do estado para a realização de uma política pública. Dessa maneira, o enfoque desta pesquisa é verificar o processo de desenvolvimento dos Circuitos 
Turísticos em Minas Gerais, enquanto política pública, e a maneira como essa política vem sendo gerida para um melhor aproveitamento do turismo no estado.

Este estudo de caso foi estruturado em quatro tópicos, além dessa introdução. O primeiro demonstrou os conceitos relacionados a atividade turística no estado, no segundo consistiu em dados sobre as políticas públicas para o turismo. No terceiro tópico destaca-se o objeto de estudo desta pesquisa através da criação da política pública de turismo em Minas Gerais. No tópico seguinte são acrescidos informações e dados sobre o desenvolvimento dos Circuitos Turísticos como uma política pública de turismo. Por fim, foram feitas as conclusões e as considerações da pesquisa, evidenciando o desenvolvimento turístico sustentável, através da atuação do estado, como um modelo de política pública de turismo para outros estados brasileiros.

Em termos metodológicos este artigo, conforme Gil (1991) tem a natureza dos estudos compreendida em uma pesquisa básica, gerando novos conhecimentos que envolvem verdades e interesses universais. Em relação à abordagem do problema considera-se uma pesquisa qualitativa através da análise indutiva dos dados, ou seja, adequada para se obter um conhecimento mais profundo de casos específicos (DENCKER, 1998). Quanto ao objetivo este trabalho foi delineado sob a forma de uma pesquisa exploratória, ou seja, buscou-se aprimorar as idéias a serem estudadas através de um planejamento flexível. Já a pesquisa como meio, caracterizou-se através dos procedimentos técnicos bibliográfico e documental, fazendo uso de métodos de coleta de dados como manejo de documentos de acervo e material secundário, entrevistas estruturadas com pessoas experientes e a observação participante.

$\mathrm{O}$ estudo requereu uma fase preliminar de levantamento e revisão da literatura existente (livros, artigos científicos e material disponibilizado na internet) para a elaboração conceitual e definição dos marcos teóricos. A partir disso, para a análise dos dados utilizou-se materiais sem tratamento analítico e conservados em arquivos de instituições públicas e privadas, além desses utilizou-se documentos de segunda mão como relatórios de pesquisa e empresas, e dados estatísticos do Instituto Brasileiro de Geografia e Estatísticas - IBGE e Instituto Brasileiro de Turismo EMBRATUR. Ainda obteve-se a observação participante da pesquisadora no ambiente de 
pesquisa $^{2}$, na busca de dados in loco sobre o assunto estudado, assim finalizando-se com entrevistas estruturadas, através de perguntas determinadas pôde-se ter o levantamento de experiências que não foram possíveis de encontrar em registros ou fontes documentárias.

Desta forma, para iniciar uma discussão que possibilite compreender o desenvolvimento do turismo por meio de uma política pública, através do estudo de caso dos Circuitos Turísticos em Minas Gerais, tornou-se necessário, primeiramente, construir um esquema de referência conceitual em cima de reflexões sobre a atividade turística no estado e políticas públicas para o turismo.

\section{O Despertar da Atividade Turística no Estado}

Teoricamente é o Estado, por meio de agentes eleitos pela maioria da população, quem deve buscar o desenvolvimento turístico que traga benefícios à coletividade. As estratégias para que esta meta, intrínseca ao espírito público, seja alcançada passam necessariamente pela formulação de uma política nacional norteadora.

O setor público vê o turismo como fonte de divisas, de suma importância para manter as contas externas superavitárias. Vê também como uma oportunidade de gerar empregos em regiões remotas, ou para movimentar economias estagnadas por meio da distribuição de renda.

Segundo Beni (2001b), o turismo em sua característica primordial leva em conta a operacionalização do sistema que na sua maior parte é processada pela iniciativa privada, cabendo ao Estado o processo de normatização e controle, o qual não significa apenas examinar se os planos estão sendo executados corretamente, mas sim avaliá-los, e, caso necessário, alterálos, pois a administração é o único controle efetivo de que se dispõe para indicar as causas dos desajustes e determinar procedimentos de correção e de retorno ao equilíbrio, a fim de otimizar as relações entre funções e operadores. Da mesma forma que ao Estado compete o investimento social não só na infra-estrutura de apoio à atividade, mas também na implantação de programas

\footnotetext{
${ }^{2} \mathrm{O}$ ambiente de pesquisa utilizado pela pesquisadora abrangeu a Secretaria de Estado de Turismo de Minas Gerais, com uma carga horária parcial de120hs de estágio de conclusão de curso.
} 
de turismo socializado, com o objetivo de facilitar o acesso ao turismo as classes menos favorecidas economicamente.

O processo de planejamento da atividade turística envolve vários atores de diversos segmentos, por conseqüência de seu efeito multiplicador na economia, tendo em vista o fato da relação dos agentes privados com o Estado ter como resultado o preenchimento de lacunas nos serviços e programas estatais, mobilizando participação da comunidade, planejando e implementando projetos, ou seja, atingindo objetivos que os órgãos públicos muitas vezes não são capazes de alcançar. (DIAS, 2003)

Essa sensibilidade e a necessidade de um engajamento sempre crescente do setor privado ao mercado descentralizam o papel do governo no sentido operacional, mas não diminuem o seu controle. O governo ainda detém a responsabilidade pela aceitação completa do tipo de turismo desenvolvido, assim como a responsabilidade total, coletiva, de assegurar que os benefícios auferidos com o turismo, inclusive os financeiros, não sejam obtidos em detrimento das necessidades sociais, culturais e ambientais.

O governo é o guardião da sociedade e, essencialmente, deve decidir o tipo de desenvolvimento aceitável. Pode ser que hoje esteja em moda reduzir a função do governo no planejamento do desenvolvimento, mas, no turismo, onde se podem gerar efeitos de demonstração de força, o governo ainda desempenha um papel importante como árbitro final dos critérios e de aceitabilidade (LICKORISH e JENKINS, 2000, p. 225). Além disso, cabe ao governo federal orientar a Política Nacional de Turismo, coordenando as iniciativas e adaptando-as às reais necessidades de desenvolvimento econômico e cultural da sociedade.

O Brasil, detentor de uma vasta coleção de riquezas paisagísticas e de diversidade biológica e cultural de alto interesse para o turismo doméstico e internacional, demonstra a necessidade de instrumentos públicos legais, tanto de incentivo para o turismo mais responsável como de controle para o ordenamento e uso equilibrado dos espaços turísticos.

Dentro os instrumentos políticos disponíveis, uma legislação clara tem um papel de destaque por ordenar não só o funcionamento do setor privado, mas, sobretudo, deixar claro o papel dos governos no desenvolvimento do turismo. 
Deste modo, a estratégia da construção de políticas públicas deve contemplar uma maior participação da sociedade como um todo, que apresentam um domínio de aspectos inerentes ao turismo que contribuem para resultados mais efetivos da ação governamental no setor, assunto esse apresentado na seqüência.

\section{Políticas Públicas para o Turismo}

Como visto, a atividade turística para o Estado inicia-se por meio das políticas públicas, neste sentido, Barretto, Burgos e Frenkel (2003, p. 33) entendem que:

O papel das políticas públicas deveria ser o de propiciar o desenvolvimento harmônico dessa atividade. Cabe ao Estado construir a infra-estrutura de acesso e a infra-estrutura básica urbana - que também atende a população local - e prover de uma superestrutura jurídico-administrativa (secretarias e similares) cujo papel é planejar e controlar os investimentos que o Estado realiza.

Dessa forma, toma-se por base que política pública são ações designadas ao interesse da sociedade, onde o governo decide o que faz através de projetos, programas para segmentos específicos da sociedade.

A importância da implantação de uma política de turismo é discutida por Beni (2001b, p. 177) ao afirmar que ela:

É a espinha dorsal do 'formula' (planejamento), do 'pensar' (plano), do 'fazer' (projetos, programas), do 'executar' (preservação, conservação, utilização e ressignificação dos patrimônios natural e cultural e sua sustentabilidade), do 'reprogramar' (estratégia) e do 'fomentar' (investimentos e vendas) o desenvolvimento turístico de um país ou de uma região e seus produtos finais.

A política de turismo é a forma na qual o poder público intervêm no setor. Essa é uma tarefa dispendiosa e os governos devem se conscientizar dos riscos e desafios envolvidos. Talvez, a principal vantagem do envolvimento do Estado seja evitar o desenvolvimento desenfreado, motivado unicamente pelo lucro por parte das empresas, o que pode ser prejudicial para o futuro do turismo no país como um todo. (ABDEL-WAHAB, 1974)

A obtenção de uma política integrada do turismo no âmbito federal, estadual e municipal deve ser matéria de responsabilidade de todo o segmento do turismo, seja público ou privado. Assim, a 
política nacional de turismo terá sua efetividade e legitimidade ampliada na medida em que for apoiada na mais larga base representativa dos interesses do turismo, garantindo seu desenvolvimento e minimizando seus efeitos negativos.

Por ser um fenômeno tão complexo, o turismo tem vários departamentos ministeriais que são responsáveis por encontrar soluções para o problema do desenvolvimento. As organizações privadas que representam o turismo devem ter sustentação moral e financeira suficientes para ter influência política na operacionalização das ações no setor. Nesta pesquisa pressupõe-se que a cooperação e integração entre o Estado e os agentes privados são necessárias para que ocorra um desenvolvimento amparado nas premissas do crescimento e desenvolvimento do turismo.

Para Nogueira (1983) é fundamental que se considere a atuação desses dois grupos no processo decisório, já que a política pública do turismo é regida tanto pelo governo quanto pela iniciativa privada.

Esse papel terá importantes implicações para o desenvolvimento da política turística no acúmulo de forças, buscando gerar o planejamento turístico público, especialmente a partir das abordagens comunitária e sustentável que se tornam interesses locais relevantes para o progresso da atividade turística.

Além disso, o Plano Nacional de Turismo - PNT (MTUR, 2003, p. 12) complementa através da política nacional de turismo a preocupação com a descentralização da gestão do turismo, "atingindo em última instância o município, onde efetivamente o turismo acontece". Dentro dessa política de descentralização e participação, os municípios serão incentivados a criar os Conselhos Municipais de Turismo. Assim para colocar em prática uma das ações do PNT dentro dos seus sete Macro Programas que tem como contribuição atingir os compromissos estabelecidos nos objetivos e metas para o turismo no período de 2003 à 2007, surge a partir da Estruturação e Diversificação da Oferta Turística (Macro Programa 4), o Programa de Roteiros Integrados.

Dessa forma, este programa busca a valorização e o respeito às especificidades locais e o envolvimento de todos os setores ligados ao turismo, buscando de forma participativa com órgãos públicos, privados, entidades civis e comunidade, a implementação de nove módulos operacionais que não são necessariamente seqüenciais: Sensibilização, Mobilização, 
Institucionalização de Instância de Governança Regional, Elaboração do Plano Estratégico de Desenvolvimento do Turismo Regional, Implementação do Plano Estratégico de Desenvolvimento do Turismo Regional, Roteirização Turística, Sistema de Informações Turísticas do Programa, Promoção e Apoio à Comercialização, Sistema de Monitoria e Avaliação do Programa.

Assim para uma melhor compreensão que envolve a política pública de turismo, destaca-se a seguir conceitos sobre os Circuitos Turísticos no contexto trabalhado pelo único estado no Brasil - Minas Gerais.

\section{A Criação da Política Pública de Turismo de Minas Gerais}

Minas Gerais, por muito tempo trabalhou apenas com os destinos turísticos das cidades históricas e termais, razão esta que estes dois destinos precisavam ser readequados. Esta revitalização vem se dando por meio da institucionalização e estruturação dos Circuitos Turísticos - Política Pública de Turismo do Estado, a fim de aumentar a permanência e o fluxo de visitantes nas regiões.

A descentralização e a regionalização das ações, encurtando as distâncias criadas pela burocracia entre o Estado e os municípios de cada região, é a principal contribuição da política dos Circuitos Turísticos.

Com a criação da Secretaria de Estado de Turismo em 1999, passa-se a ter então um grande incentivo para colocar em prática uma política descentralizada voltada para este segmento. Como gestor, parceiro e facilitador, o Estado se responsabiliza pela criação do projeto dos Circuitos Turísticos, o Governo Federal aparece como grande incentivador, enquanto a iniciativa privada surge como apoiadora e "patrocinadora", e a sociedade como ator principal, ajudando na conscientização de todos os munícipes. Assim, afirmando a idéia de Beni (2001b) onde ao Estado cabe o processo de normatização e controle, implantando programas de turismo socializado, como o caso dos Circuitos Turísticos, e a iniciativa privada investindo na qualificação de mão-deobra e aperfeiçoamento de pessoal, operacionalizando, assim, o sistema do turismo. 
Para tanto, a SETUR (2003), propós seus próprios objetivos para o projeto de criação dos Circuitos Turísticos, os quais são:

- Criar novos destinos turísticos no estado de Minas Gerais

- Descentralizar as políticas de desenvolvimento do segmento turístico;

- Desenvolver o turismo regional de forma sustentável;

- Aumentar o fluxo e a permanência do turista, gerando renda e empregos (diretos/indiretos);

- Resgatar, valorizar e preservar todo o patrimônio histórico, cultural e natural;

- Movimentar e aumentar a arrecadação dos municípios e consequentemente a do Estado;

- Incorporar a sociedade em um planejamento integrado, valorizando o turismo regional;

- Incentivar todos os segmentos da "Cadeia Produtiva".

Dessa forma, alguns objetivos da SETUR ao projeto de criação dos Circuitos Turísticos podem ser relacionados com algumas ferramentas que Dias (2003) utiliza para a construção de uma política municipal de turismo, conforme Quadro 1.

Com base na relação dos dados do Quadro 1, pode-se concordar com Beni (2001a) que ao a SETUR implantar a política pública dos Circuitos Turísticos, a sua importância se dá pela formulação do planejamento; o pensar do plano; o fazer dos projetos e programas; o executar da preservação, conservação; o reprogramar das estratégias e o fomentar dos investimentos e vendas.

\section{Quadro 1: Objetivos e Ferramentas para a Construção de uma Política Pública de Turismo}

\begin{tabular}{|c|c|}
\hline $\begin{array}{l}\text { SETUR (2003) } \\
\text { OBJETIVOS }\end{array}$ & $\begin{array}{l}\text { DIAS (2003) } \\
\text { FERRAMENTAS }\end{array}$ \\
\hline $\begin{array}{l}\text { - Criar novos destinos turísticos no Estado de Minas } \\
\text { Gerais; } \\
\text { - Desenvolver o turismo regional de forma sustentável; }\end{array}$ & $\begin{array}{l}\text { Identificar um modelo turístico baseado nas } \\
\text { características dos recursos turísticos, oferta atual, } \\
\text { mercados emissores, equilíbrio da exploração dos } \\
\text { atrativos, considerando a urbanização e o grau de } \\
\text { organização do território, em relação ao patrimônio e } \\
\text { a paisagem urbana, respeitando a identidade cultural } \\
\text { e a premissa da sustentabilidade. }\end{array}$ \\
\hline $\begin{array}{l}\text { - Resgatar, valorizar e preservar todo o patrimônio } \\
\text { histórico, cultural e natural; }\end{array}$ & $\begin{array}{l}\text { Criar uma "cultura turística" na comunidade local, } \\
\text { através de campanhas de conscientização turística, }\end{array}$ \\
\hline
\end{tabular}




\begin{tabular}{|l|l|}
\hline - Incentivar todos os segmentos da cadeia produtiva; & $\begin{array}{l}\text { iniciando nas escolas, e mostrando a comunidade o } \\
\text { papel do turismo como gerador de renda e empregos. }\end{array}$ \\
\hline $\begin{array}{l}\text { - Incorporar a sociedade em um planejamento } \\
\text { integrado, valorizando o turismo regional; }\end{array}$ & $\begin{array}{l}\text { Gestão do turismo na escala local, compartilhando } \\
\text { responsabilidades entre o setor público e setor } \\
\text { privado, visando o bem-estar da comunidade local e } \\
\text { a sustentabilidade dos recursos. }\end{array}$ \\
\hline
\end{tabular}

Fonte: Produzido pela autora, 2005.

Assim, buscando essas premissas iniciou-se as primeiras oficinas participativas em fevereiro de 2001, ainda na gestão passada (1999/2003), para a construção da política pública de turismo em Minas Gerais. Ao final da gestão 1999/2002, foram realizadas 54 oficinas, atingindo mais de 400 municípios, contando com a participação direta de mais de 3 (três) mil pessoas. (SETUR, 2002)

As oficinas participativas foram ferramentas de um processo de sensibilização e despertar do próprio poder público e das comunidades locais. Foi a partir delas que aconteceu o engajamento com responsabilidade de todas as lideranças locais, tanto no planejamento e priorização das ações, quanto na execução das propostas.

O maior objetivo das oficinas, coerente com a visão estratégica da então gestão da Secretaria de Estado de Turismo, era motivar os representantes dos municípios para a organização de grupos representativos, na gestão do turismo regional com iniciativa e estratégias de desenvolvimento turístico local.

O eixo central das oficinas era a organização regional para o desenvolvimento turístico. As oficinas tinham a duração de dois dias. Eram iniciadas por uma palestra do então Secretário de Estado de Turismo, Manoel Costa, grande idealizador de todo o processo. A presença e permanência do Secretário em todas as oficinas foram fundamentais para dar credibilidade ao projeto. Sua palestra focava a organização regional e a "cadeia produtiva do turismo". Assim, tendo por base as orientações da palestra, os municípios se dividiam em grupos de acordo com afinidades culturais, sociais, econômicas e limitações geográficas.

Essa metodologia foi adotada como tentativa de inverter a antiga concepção de administração centralizada, onde normalmente a comunidade recebia algum ensinamento de um corpo técnico, que desconhece a realidade local. Com tal enfoque o trabalho buscou discutir a atividade turística, explorando a experiência de cada município e contextualizando-o regionalmente. Os participantes destacavam a importância do turismo em seus municípios, os pontos fortes e fracos, 
os entraves e as oportunidades, a regionalização como opção para o desenvolvimento turístico, o papel de cada participante, as parcerias, as prioridades, e os próximos passos para implementação do processo. Finalizando foram realizadas plenárias onde todos os participantes se reuniam novamente para apresentação dos resultados de cada grupo.

Conforme relatório das atividades realizadas pela SETUR (2002), é importante mencionar que durante as discussões a visão paternalista dos participantes de que o Estado era o grande responsável por todas as ações e soluções para o desenvolvimento turístico era predominante. Ao finalizar os trabalhos os grupos conseguiam enxergar nítida e claramente que $80 \%$ das ações e atividades a serem desenvolvidas dependiam inteiramente do poder público local, iniciativa privada e da própria comunidade. Ou seja, procedendo as idéias de Dias (2003) que o planejamento regional só é possível até o momento que o planejamento estratégico do desenvolvimento se dá sob o controle de agentes que não necessariamente estão vinculados ao Estado.

Assim, pode-se concordar que os participantes seguiram uma linha de raciocínio baseada nos pensamentos de Petrocchi (1998), ou seja, definindo decisões básicas que articulam a política turística da região, estabelecendo diretrizes para desenvolvimento do turismo, a posição que se deseja ter nos mercados e as estratégias dos programas e ações.

Além disso, as propostas das oficinas foram elaboradas a partir da lógica da seguinte estratégia de ação:

- Objetivo Superior: Aumentar o fluxo e a permanência dos turistas nos circuitos.

- Objetivo do Plano: Desenvolvimento da Infra-Estrutura Turística para os circuitos.

- Objetivos do Programa: Melhorias de atrativos, transportes, hospedagem, alimentação, serviços turísticos, comercialização e gestão.

Essas oficinas com vistas à organização e criação dos Circuitos Turísticos permitiram realizar um pré-levantamento dos atrativos, acessos e transportes, hospedagem, alimentação e serviços existentes nos municípios que delas participaram. Com isso, hoje tem-se um inventário 
preliminar dos problemas que afetam esses elos da cadeia turística, assim como das soluções propostas para resolvê-los e dos parceiros capazes de contribuir nesse sentido.

Por outro lado as oficinas também permitiram detectar que os agentes envolvidos no turismo dos municípios e circuitos, em geral, não tratam ativa e adequadamente da comercialização de seus produtos turísticos, nem possuem sistemas de gestão que articulem os diversos elos da cadeia de turismo e coordenam seu funcionamento.

Além dessas oficinas de participação a Secretaria de Turismo de Estado de Minas Gerais, identificou a necessidade de uma maior integração entre a diretoria das instituições regionais, os gestores dos circuitos e equipes da Secretaria. Para tanto foi realizada mais duas oficinas de monitoria do processo de criação dos circuitos, nos municípios sede de Esmeraldas e Piumhí, nos meses de maio e agosto de 2002. As pessoas envolvidas no processo foram convidadas a participar de uma oficina de trabalho, no enfoque participativo, a fim de consolidar o processo integrado de microrregionais.

Nestas oficinas houve até a conclusão de um conceito prévio sobre o que é um Circuito Turístico, não ficando muito longe do atual disposto pelo Decreto Estadual:

Circuito Turístico é o conjunto de municípios de uma mesma região, com as comunidades culturais, sociais e econômicas unidas para organizar e desenvolver a atividade turística regional de forma sustentável, por meio da integração contínua dos municípios, consolidando um identidade regional. (III Oficina dos Circuitos Turísticos - Piumhí - MG, 2002)

Dessa forma, por meio do associativismo firmado, os respectivos atrativos, equipamentos e serviços turísticos se complementariam e enriqueceriam, sobremaneira, a oferta turística regional, com expressivos ganhos para os turistas e as comunidades envolvidas. Para os turistas, as visitas se tornariam mais diversificadas e atraentes; para as comunidades, haveria novas possibilidades em relação a trabalho e renda, com reflexos positivos na qualidade de vida.

O Governo do Estado de Minas Gerais identificou um novo padrão de relacionamento com a sociedade, sem o qual tornar-se-ia impossível construir um projeto de desenvolvimento e fortalecimento da cidadania, bem como renovar o estilo de planejamento governamental. O que reforça através do guia de desenvolvimento em turismo sustentável da OMT (1993) que a 
cooperação entre os parceiros é primordial para a conquista do turismo contínuo e sustentável, melhorando a qualidade de vida local.

Assim, a atenção dos municípios se voltava para um interesse em comum: buscar na atividade turística alternativas para alcançar o desenvolvimento auto-sustentável. Implantou-se, então, um novo modo de produzir, com alicerces na sustentabilidade, que traz benefícios duradouros para as regiões com potencial turístico e garante o envolvimento gradativo das comunidades, o estímulo a uma forma de associativismo que resultaria na criação dos Circuitos Turísticos de Minas Gerais.

\section{Os Circuitos Turísticos}

A política pública de Circuitos Turísticos do estado de Minas Gerais, objetiva fomentar a atividade turística mineira como fator de desenvolvimento social, econômico e cultural, por intermédio da Secretaria de Estado de Turismo. Trata-se de dezenas de circuitos constituídos sob forma jurídica de associações, com estatutos próprios e que contemplam em sua estrutura o poder público, a iniciativa privada e a sociedade civil.

Pode-se então se basear em Barretto; Burgos e Frenkel (2003) que o papel da política pública de turismo em Minas Gerais é de propiciar o desenvolvimento harmônico da atividade, cabendo ao órgão responsável por essa ação - SETUR, planejar e controlar os investimentos que o Estado realiza.

Esta política se reflete no número de Circuitos Turísticos já legalmente constituídos no Estado, que já perfazem num total de 51, organizados e institucionalizados, abrangendo 546 municípios mineiros, ou seja, 64\% do Estado. Entre eles destacam-se os primeiros Circuitos Turísticos a serem formados - Circuito Turístico das Águas e Circuito Turístico do Ouro ${ }^{3}$.

\footnotetext{
${ }^{3}$ As denominações de Circuito Turístico das Águas juntamente com o Circuito Turístico do Ouro já existiam desde do século XVIII, mas não na forma de organização proposta pela metodologia da SETUR, os municípios até se reuniram anteriormente, mas essas reuniões não passavam de um fórum de discussões sobre turismo, pois não foram realizadas ações concretas de trabalho em conjunto ou atividades compartilhadas entre esses municípios. De certa forma, serviu para o amadurecimento dos conceitos da atividade turística nessas regiões, que historicamente já recebiam turistas.
} 
Dessa maneira, a formação dos Circuitos Turísticos tem como missão:

- Identificar os municípios que tenham uma afinidade turística ou que se complementam turisticamente, localizados num raio aproximado de $100 \mathrm{~km}$;

- Mobilizar representantes do poder público, iniciativa privada e comunidade de cada município interessado;

- Realizar reunião de integração com a participação dos técnicos da SETUR;

- Definir através da identidade comum regional dos municípios participantes, o nome do Circuito Turístico;

- Definir o tipo de entidade gestora: Associação, Agência de Desenvolvimento, ONG;

- Elaborar um Estatuto/Regimento Interno (Registrar).

No decorrer do processo, os Circuitos Turísticos sentiram a necessidade de uma forma de organização legítima e reconhecida. Alguns optaram por associações, outros por organizações não governamentais, agências de desenvolvimento regionais e até mesmo OSCIP- Organização da Sociedade Civil de Interesse Público. Os Circuitos não tem a conotação de organizações microrregionais de prefeitos, participam deles empresários, comunidade, instituições de classe, o terceiro setor, instituições de ensino e as prefeituras que constituem um conselho regional.

Segundo relatório da Secretaria de Estado de Turismo de Minas Gerais

O circuito é administrado por uma entidade sem fins lucrativos com autonomia administrativa e financeira, regida por um estatuto, membros da sociedade civil e do poder público, e com a participação mais ativa das empresas que compõem a Cadeia Produtiva do Turismo. SETUR (2002)

Assim para a SETUR (2003), as vantagens de se formar um Circuito Turístico são:

- Potencialização dos esforços para promover o desenvolvimento turístico;

- Buscar meios para capacitação profissional no setor;

- Aumento do fluxo e permanência do turista na região;

- Preservação e resgate dos patrimônios culturais e naturais;

- Melhoria da qualidade de vida do município e o atendimento ao turista. 
A partir dessa formação surge a necessidade de um gestor para o circuito. Seria o responsável, executor das ações definidas nas reuniões e o elo de ligação entre o Circuito Turístico/Secretaria de Estado de Turismo/municípios/comunidades e parceiros. No início a SETUR subsidiou por um período de três meses a remuneração desse gestor contribuindo com os municípios para que os primeiros passos pudessem ser dados. Quem indicava e escolhia o gestor era o próprio Circuito, por isso, o gestor passou a ser fundamental, com perfil de profissional do turismo, empreendedor, versátil, dinâmico, comunicativo, carismático, com espírito de liderança, que resida na região que abrange o circuito, lidar com as diferentes posições dos participantes do circuito e ter uma visão macro da cadeia produtiva do turismo.

Já os dirigentes que fazem parte do Circuito Turístico tem como funções: fazer cumprir o Estatuto e o Regimento Interno; dirigir e coordenar todas as ações do Circuito Turístico; elaborar o plano de ações e o orçamento anual do Circuito Turístico; elaborar periodicamente relatório de prestação de contas referente a: recursos financeiros, convênios firmados e orçamentos e outras ações.

Algumas regras foram sugeridas pela Secretaria para a organização dos circuitos como a criação de uma entidade para sua coordenação, contando com diretoria e, se necessário, com um gestor, executivo pago pelo próprio circuito. Isto significa autonomia para o circuito e menos ingerência do poder público que, no entanto, pode ser cobrado para o cumprimento de suas tarefas formais como, por exemplo, a infra-estrutura necessária de sustentação ao incremento turístico daquela região.

A SETUR apenas acompanha o processo de organização dos Circuitos Turísticos, não intervém nas decisões, orienta para que eles obtenham melhores resultados. Como a proposta da política pública de turismo de Minas Gerais foi um processo inovador, não existiu modelos e receitas que poderiam ser copiadas ou adaptadas, os modelos de organização e gestão, portanto se construíram a partir das experiências de cada região. Não houve nenhuma influência da SETUR para uniformizar ou padronizar o tipo de organização e os métodos de gestão dos circuitos. Conforme relatórios da SETUR (2002), verificou-se posteriormente que a forma jurídica com melhor desempenho foi a de organizações em forma de associações. 
No entanto, percebe-se ainda que é preciso levar ao conhecimento das autoridades públicas e empreendedores dessas regiões as informações necessárias sobre o "Projeto Circuitos Turísticos" do Estado, visando a inclusão de todos os 853 municípios mineiros nessa importante política governamental de desenvolvimento do turismo, possibilitando assim a democratização de todos os seus benefícios. Para isso, precisa-se disponibilizar aos interessados os principais instrumentos necessários à implantação de um circuito e as estratégias a serem implementadas para a sua correta e eficiente administração.

Para trabalhar turisticamente, por meio de um circuito, é preciso que se pense coletivamente, para isto é importante que se tenha em mente alguns princípios básicos desta política de circuitos: é necessário sempre que se promova uma ação conjunta e ordenada entre os membros, mas não esquecendo o planejamento individual; implantar um projeto de exploração turística sustentável; buscar a inclusão social para os locais; buscar estruturar um produto âncora competitivo e diferenciado, em cada município do circuito; criar um roteiro, se possível; que englobe todos os membros e lançá-lo ao mercado via operadoras e agências; e criar pacotes com roteiros múltiplos dentro do circuito.

Estando, então, o circuito bem estruturado, torna-se viável a elaboração de uma estratégia de exploração do mercado regional, com atração individual de cada município membro, ou nacional e internacional, através de uma atuação em conjunto entre todos os seus membros.

Essa política pública de turismo abrange um destino turístico formado por municípios de uma mesma região, com afinidade para a exploração da atividade turística. Tendo por base um pólo com maior capacidade de atração e dotado de uma melhor infra-estrutura de atendimento, o Circuito Turístico agrega outros atrativos, permitindo ao visitante a oportunidade de conhecer melhor a região e o seu potencial.

Como já visto na teoria anteriormente, a política pública para o turismo é tudo o que os governos decidem fazer ou não em relação ao setor. Entretanto, percebe-se que as decisões em favor do mesmo carecem de eficiência no que tange às implementações de tais políticas, havendo uma variação do envolvimento dos órgãos governamentais no que se refere às políticas para o turismo. No caso dos Circuitos Turísticos há uma distância entre as leis e a realidade encontrada em cada cidade pertencente ao circuito. As diferenças das relações políticas entre os municípios 
constituintes do circuito, assim como as intenções em relação ao desenvolvimento do turismo colocam as localidades em patamares diferentes, às vezes, impossibilitando um desenvolvimento integrado do circuito como um todo.

Durante a gestão da Secretaria de Estado de Turismo 1999/2003 foram induzidos a organização de 43 Circuitos Turísticos. A metodologia adotada de construção participativa do processo foi uma das grandes responsáveis por garantir a continuidade política por parte do Estado nesta atual administração 2003/2007. A comunidade local, iniciativa privada e poder público municipal fizeram o pleito em favor da continuidade da política dos Circuitos Turísticos ainda durante o processo eleitoral para todos os candidatos a governo do Estado, dessa forma, foi elaborado um documento oficial, assinado por representantes de 38 circuitos e entregue aos candidatos.

Assim, o atual governador Aécio Neves, não só prosseguiu com a política pública dos Circuitos Turísticos através da SETUR em 2003, mas também institucionalizou os circuitos, conforme Decreto Estadual $n^{\circ}$ 43.321. Esse foi um passo importantíssimo para de fato legitimar os Circuitos Turísticos mineiros. Além disso, elegeu os Circuitos Turísticos como uma das três prioridades do Governo atual para o desenvolvimento do turismo, e ainda outro passo fundamental a destacar foi a Resolução 006/2005 da SETUR que pretende instituir o Certificado de Reconhecimento dos Circuitos Turísticos.

\section{Considerações e Conclusões Finais}

O presente estudo de caso evidenciou que o planejamento para o desenvolvimento de um turismo sustentável não pode ser desvinculado da atuação do Estado como agente primordial para a elaboração e execução de uma política pública para o turismo.

No caso dos Circuitos Turísticos, verificou-se que a organização dessa política pública vem sendo desenvolvida em alicerces sustentáveis buscando expandir seus conceitos em todo estado de Minas Gerais, buscando concretizar os ideais do Programa de Regionalização do Turismo proposto pelo Ministério de Turismo, mostrando assim, o desempenho e comprometimento do atual governo para com as premissas de fomento do turismo e contribuindo de exemplo para diversos estados da federação que buscam desenvolver a atividade turística na sua região. 
Destaca-se assim que a prioridade que o governo de Minas Gerais vem colocando em relação aos Circuitos Turísticos certificados, que hoje contabilizam em 20 no total, vem despertando interesse em diversos circuitos ainda não certificado e que buscam financiamento em projetos de desenvolvimento do turismo em sua região. Essa foi a maneira "saudável" que a SETUR encontrou em buscar critérios para priorizar os Circuitos Turísticos interessados e ao mesmo tempo direcionar seus recursos orçamentários.

Verifica-se ainda que alguns fatores possam influenciar na continuidade ou paralisação dos Circuitos Turísticos, um deles é a localização geográfica da região que sendo próxima a grandes mercados emissores como São Paulo e Rio de Janeiro, tem maior probabilidade de êxito, assim como, no eixo da Estrada Real onde encontram os Circuitos Turísticos que fazem parte do plano estruturador do governo. Outro fator é a figura do gestor, que se não possuir o perfil adequado para o cargo pode levar o circuito a cair em descrédito junto aos municípios participantes. A capacitação contínua desse profissional poderia ser mais bem trabalhada através de cursos profissionalizantes, alguns já realizados, por parceiros como SEBRAE, SENAC e Instituto de Hospitalidade. A comunidade local é outra parte que deve se interessar em participar de todas as etapas do processo de formação do Circuito Turístico, pois é o principal beneficiário do desenvolvimento gerado pelo turismo.

Ainda não poderia deixar de citar uma importante preocupação da continuidade da política pública dos Circuitos Turísticos em Minas Gerais em relação a mudança de mandato político. Os Circuitos Turísticos não podem ser instrumento de política eleitoral, devem permanecer neutros e conscientizar os novos governadores e prefeitos da importância da instituição levando-os a efetiva participação. A institucionalização e priorização por parte do Estado com os Circuitos Turísticos sem dúvida transmite uma certa tranqüilidade para prosseguimento do processo.

Acredita-se que a regionalização da atividade turística em Minas Gerais está no caminho certo, até porque é visto como o único meio viável até o presente momento, pelo tamanho do território que o Estado abrange. Embora algumas regiões tenham adormecido e outras despertado, há ainda o conceito e exemplos claros de que o caminho para o desenvolvimento do turismo passa pelo agrupamento de esforços e perseverança de pessoas que acreditam e se interessam pelo crescimento do setor turístico. Pois, para tanto, acrescenta-se que não há como trabalhar Circuitos 
Turísticos sem tratar dos municípios, que muitas vezes estão em situação precária de desenvolvimento turístico.

No mais, destaca-se de forma relevante que Minas Gerais é o único estado a trabalhar com a proposta de Circuitos Turísticos o que ressalta através da letra "j" do número I do Artigo $2^{\circ}$ da Resolução 006/2005: “Ter as instituições a denominação precedida de Circuito Turístico”. Isso que dizer que em Minas Gerais foi adotada oficialmente a nomenclatura "Circuito Turístico" para as organizações regionais dessa natureza. E ainda nota-se que a política pública dos Circuitos Turísticos está se fortalecendo cada vez mais, pois já possui parcerias com outros órgãos públicos que reconhecem a política de turismo estadual, integrando-a em seu foco de trabalho, como o caso DETEL - Departamento Estadual de Telecomunicações, DER - Departamento de Estrada e Rodagem e IGA - Instituto de Geociências Aplicadas.

Assim, deve-se atentar para o fato de que as políticas públicas relacionadas ao desenvolvimento do turismo devem ser definidas de modo compartilhado entre o setor público e a iniciativa privada, as entidades de classe e comunitárias, organizações não governamentais ambientalistas e sociais, universidades, órgãos de fomento e de capacitação, e com a comunidade receptora, os quais possuem papéis específicos e serão agentes fundamentais para colocar as políticas e seus instrumentos em funcionamento contínuo, tornando-o sustentável.

\section{Referências Bibliográficas}

ABDEL-WAHAD, Salah E. 1974. Elements of state policy on tourism: with special em phasis on developing countries. USA: Cornell.

BARRETTO, Margarita; BURGOS, Raúl; FRENKEL, David. 2003. Turismo, políticas públicas e relações internacionais. São Paulo: Papirus.

BENI, Mário C. 2001a. Análise estrutural do turismo. 3.ed. São Paulo: SENAC.

2001b.A política de turismo. In: TRIGO, Luiz Gonzaga Godoi (Org.). Turismo: como aprender, como ensinar. São Paulo: SENAC.

DENCKER, Ada Freitas Maneti. 1998.Métodos e técnicas de pesquisa em turismo. São Paulo: Futura.

DIAS, Reinaldo. 2003. Planejamento do turismo: política e desenvolvimento do turismo no Brasil. São Paulo: Atlas. 
GIL, Antônio C. 1991. Como elaborar projetos de pesquisa. 3.ed. São Paulo: Atlas.

LICKORISH, Leonard J. e JENKINS, Cason L. 2000. Introdução ao turismo. Rio de Janeiro: Campus.

MTUR. Ministério do Turismo. Plano Nacional de Turismo. 2003. Diretrizes, Metas e Programas. 2003/2007. Disponível em: <http://institucional.turismo.gov.br/>. Acesso em: jul. 2005.

NOGUEIRA, Mario F. G. 1983. O papel do turismo no desenvolvimento econômico e social do Brasil. Revista de Administração Pública. abr.jun 1983. Rio de Janeiro: Fundação Getúlio Vargas, p. 37-54.

OMT - World Tourism Organization. 1993. Global tourisme forecasts for the year 2000 and beyond. Madri.

PETROCCHI, Mário. 1998. Turismo: planejamento e gestão. São Paulo: Futura.

SETUR. 2002. Minas revolucionou o turismo: a descoberta da potencialidade mediterrânea. Belo Horizonte.

SETUR. 2003. Relatório de atividades da SETUR. 2003. Belo Horizonte.

III OFICINA DOS CIRCUITOS TURÍSTICOS. 2002. Secretaria de Estado de Turismo de Minas Gerais. Piumhí.

Recebido em: 05/08/2006 ( $1^{\mathrm{a}}$ versão) $07 / 01 / 2008\left(2^{\mathrm{a}}\right.$ versão)

Aprovado em: 14/01/2008 